\title{
The extent of non-compliant plumbing components used in South Africa
}

\author{
KP Lobanga ${ }^{1}$, JE van Zyl1* and AA llemobade ${ }^{2}$ \\ ${ }^{1}$ Department of Civil Engineering Science, University of Johannesburg, PO Box 524, Auckland Park 2006, South Africa \\ ${ }^{2}$ School of Civil and Environmental Engineering, University of the Witwatersrand, South Africa
}

\begin{abstract}
High quality plumbing components are essential to ensure the efficient and safe supply of water, and minimise water losses in buildings. South African legislation requires that all plumbing components installed comply with certain standards set by the South African Bureau of Standards (SABS). Water Services Authorities are responsible for enforcing this legislation, and are allowed to set their own additional requirements for plumbing components. This study investigated the extent of non-compliant plumbing components used in South Africa through a number of methods, and concludes that compliance is roughly $50 \%$. This points to a large problem and has dire consequences for the future of effective water use and water leakage in South Africa. A worrying finding is that the level of non-compliance seems to be particularly large in low-cost housing developments. The main reasons for the low levels of compliance are a lack of enforcement at local government level and the fact that legislation does not prohibit the import and sale of non-compliant components. The paper makes a number of recommendations for improving the situation.
\end{abstract}

Keywords: plumbing components, plumbing fittings, water supply

\section{Introduction}

Freshwater is a limited resource coming under increasing pressure as human consumption increases worldwide. This is of particular concern in South Africa with an annual rainfall of less than $500 \mathrm{~mm}$, significantly lower than the world average of $860 \mathrm{~mm}$ (WRC, 2008), and classified as a water-stressed country (UNEP, 1999). It is thus critical that water is used efficiently and losses from water supply systems are minimised.

Water is abstracted from the environment, purified and delivered to consumers through a piped water distribution system. Municipal water supply systems normally terminate at the consumer property boundary, after which the installation and maintenance of the water distribution (or plumbing) system becomes the consumer's responsibility. The plumbing system is made up of various types of components (fittings), including pipes, couplings, elbows, tees, gate valves, pressure reducing valves, pressure relief valves, geysers (hot-water cylinders, also known as boilers) and taps. The plumbing system generally terminates in taps or automatically operated shut-off valves (such as a toilet cistern valve or a washing machine control valve). It is essential that plumbing components and installation practices comply with high standards to ensure that water is supplied effectively and safely to consumers.

In recent years, South Africa has seen a substantial increase in the numbers of imported and pirated plumbing components introduced onto the market, which may have significant future implications for effective water use and public health. The aim of

This paper was originally presented at the 2008 Water Institute of Southern Africa (WISA) Biennial Conference, Sun City, South Africa, 18-22 May 2008.

* To whom all correspondence should be addressed.

용 +2711 559 2345; fax: +2711 559 2343;

e-mail: kobusvz@uj.ac.za this study was to quantify the extent of non-compliant plumbing components used in South Africa, its causes and implications, and make recommendations for addressing the problem. This project focussed solely on water supply plumbing components and thus did not include drainage components.

The importance of plumbing systems is discussed in the next section, followed by a brief overview of the plumbing industry in South Africa. The work conducted to estimate the level of compliance of plumbing components is then described and discussed. The paper is concluded with a general discussion and conclusions.

\section{Importance of plumbing systems}

Water from the municipal distribution system is used for drinking, cooking and washing via a private plumbing system. It is critical that these systems are designed, installed and maintained to ensure that water is supplied effectively and safely. The World Health Organisation, the World Plumbing Council and others (WHO, 2006; Frankel, 2004) have defined a number of goals for water supply and plumbing systems. The main requirements are summarised below:

- Drinking water at the consumer's tap should be available reliably and in adequate quantities. The water should be safe at all times.

- The supply plumbing system should not be able to degrade the quality of drinking water. Plumbing materials should not contain harmful substances that can leach into the water creating health hazards.

- Each building should have an internal drinking-water piped system, supplying drinking water from a suitable number of accessible plumbing fixtures. Houses should have at least one toilet, one washbasin, one kitchen sink, one bathtub or shower, and provision for laundry facilities. For other buildings, the number and type of plumbing fixtures should be 
provided based on respective needs. Provisions should also be made for people with disabilities.

- Plumbing systems should be durable, resistant to internal and external pressures and environmental factors.

- Plumbing components and workmanship should comply with the requirements of standards.

- All new plumbing installations should be tested and disinfected .

- Water leakage and wastage should be minimised. Plumbing components should be designed, maintained, used and installed with the objective of minimising leakage and wastage.

- Hot water systems should be designed and installed in a way to avoid health hazards such as explosion and overheating.

- Building contents should be protected from adverse effects caused by a malfunction of the plumbing system.

- Plumbers should have adequate training and the public should be made aware of the dangers of poor plumbing components and work.

Other requirements include that plumbing fixture materials should be smooth, non-absorbent, non-porous and corrosionresistant. Both internal and external surfaces of plumbing fixtures should be easy to clean and free from hidden surfaces that could become fouled. Plumbing fixtures should be sufficiently durable to give satisfactory service over a long period (Jordan, 2004; Frankel, 2004 - WHO, 2006). They should be user friendly and hygienic and their surfaces should be free of sharp surfaces that may cause injury (Jordan, 2004). Potable water discharged from plumbing fixtures should be limited to a maximum flow rate depending on the requirements for water conservation (Frankel, 2004). Roof tanks and other hidden elements of the plumbing system should be provided with overflows that discharge in such a way as to act as a warning before causing damage.

Inadequate plumbing systems can have severe consequences, including the following:

- Pipes or components may leak or burst, resulting in financial losses to the building owner and/or water supply authority due to water losses, damage to property, temporary loss of use of a property, and possible replacement of the plumbing system.

- A leak or burst on a hot water pipe may also result in serious injury due to scalding, and cases of death have been reported. For instance, in November 2006, a ten-monthold baby in the UK suffered $95 \%$ burns when a fault in the plumbing system caused hot water to be released in the bedroom where she was sleeping. She died a month later (BBC News, 2008).

- Under certain conditions, inadequate plumbing systems can cause explosion of high pressure geysers, with potential injury to people and damage to property.

- Various substances, such as lead, copper, cyanide, arsenic, iron, manganese, zinc, biological and organic matter may enter the water through leaching from plumbing materials or interactions between the plumbing material and water. In serious cases, for instance when sub-standard materials are used, this may cause colour, taste and odour problems in the water, and have negative health impacts, including gastrointestinal discomfort and nausea, brain damage and cancer (EPA, 2007; Thompson et al., 2007)

- Under certain conditions, potentially contaminated return flow from geysers or fixtures may enter the plumbing system and create a health risk.
- Insufficient cleaning and disinfection of the plumbing system after installation or maintenance may cause contaminated water to be supplied.

Unfortunately it is not easy to monitor the negative health effects caused by bad-quality plumbing materials due to the fact that the metal components vary from one building to another and, in the same building the concentration of any particular metal varies at different times of a day (Thompson et al., 2007). In addition, side effects generally appear after many years of exposure and vary from one person to the next.

\section{The plumbing industry in South Africa}

\section{Role-players}

There are a multitude of institutions that play a role in the South African plumbing industry. In this section the most important institutions, their roles and processes are discussed.

\section{Department of Water Affairs and Forestry}

The Department of Water Affairs and Forestry (DWAF) acts as guardian of water resources in South Africa (DWAF, 2007) and is responsible for publishing and enforcing legislation to regulate the water sector at a national level.

\section{The South African Bureau of Standards}

The South African Bureau of Standards (SABS) is the main standards body in the country. It publishes standards, and tests and certifies plumbing components to these standards. It is important to distinguish between components that bear the SABS mark and components that have an SABS test certificate. The former is the correct and thorough process that ensures that a particular component complies with the relevant standards through regular random testing of the component and visits to the manufacturing plant by SABS staff. The latter is simply a certificate that a particular component sample has passed the relevant SABS test of compliance. The certificate is only valid for the specific component tested and provides no guarantee that other copies of the same component also comply to the SABS standard.

The main SABS standards relevant to the plumbing industry are:

- SANS 10252 Water Supply and Drainage for Buildings - Part 1: Water Supply Installations for Buildings. This standard also refers to other relevant standards that products and materials should comply to.

- SANS 10254 The Installation, Maintenance, Replacement and Repair of Fixed Electric Storage Water Heating Systems. This standard regulates geysers and associated plumbing components.

- SABS 0400 Code of Practice for the Application of the National Building Regulations. The National Building Regulations set requirements for the technical performance for all buildings constructed to ensure the health and safety of occupants. It specifies what persons may do plumbing work, but does not specify much regarding water supply plumbing components.

It was not possible to obtain a detailed list of components bearing the SABS mark from the SABS. Staff at the SABS referred us to their website, which contained a list of companies that are SABS mark holders, but not a list of the actual components that carried the mark. Where a company thus supplies some 
components that bear the SABS mark and some that do not, it was impossible to validate this with the information supplied by the SABS. In such cases we assumed that the claims of compliance of the company were accurate.

\section{Water services authorities (WSAs)}

The Water Services Act delegates to a Water Services Authority (WSA) the power to make bylaws relating to the provision of water services (RSA, 1997). A WSA is a municipality that is responsible for providing access to water services in its area of jurisdiction. WSAs are required to publish and enforce water bylaws to regulate the supply of water to consumers in their respective jurisdictions and have the power to appoint other providers and intermediaries to assist with their tasks. WSAs must also prepare and implement a Water Services Development Plan (WSDP) at intervals determined by the Minister of Water Affairs and Forestry. One hundred and sixty nine of the 284 South African municipalities are Water Services Authorities (DWAF and SALGA, 2007; DWAF, 2008).

\section{Joint Acceptance Scheme for Water Services Installa- tion Components (JASWIC)}

JASWIC is a voluntary organisation composed of WSAs and other organisations, including the SABS, the South African Water Research Commission (WRC) and Institute of Plumbing of South Africa (IOPSA). JASWIC's main goal is to assist the SABS in the setting and maintaining of national standards for water supply and sanitation, thereby promoting the prevention of water wastage, efficient use of water, efficient delivery of water services and safety of water installations (JASWIC, 2008a). JASWIC maintains a list of approved plumbing products. To qualify for inclusion in the JASWIC list, a component has to bear the SABS mark, or enter into a JASWIC Inspection Contract with the SABS (JASWIC, 1999). According to this contract, the SABS will regularly inspect the supplier's premises and conduct tests on samples of the component.

\section{Institute of Plumbing of South Africa (IOPSA)}

IOPSA is a voluntary body that represents plumbers and plumbing organisations. More than 765 plumbing companies, 3500 qualified plumbers, and $10000 \mathrm{semi}$-skilled persons working in the plumbing industry are members of IOPSA (IOPSA, 2008a). Plumbers who are members of IOPSA have to abide by a code of conduct that includes only using compliant plumbing components (IOPSA, 2008b).

\section{Educational bodies}

The main educational body responsible for plumber training in South Africa is the Construction Education and Training Authority (CETA). CETA does not offer training itself but accredits and monitors the delivery of training by accredited training providers. The basic requirement for a candidate to enrol for the plumbing learnership programme is that he/she has to be employed by a qualified plumber who provides practical training while the providers give theoretical training (DPW, 2007).

In Further Education and Training (FET) colleges, learners receive theoretical and practical training in the plumbing field and have to acquire their practical training when they start working (DPW, 2007). After completion of studies at an FET college, a learner still needs to complete the plumbing trade test before obtaining the qualification. An assistant plumber who has spent more than 5 years working under the supervision of a qualified plumber also has to pass the trade test in plumbing in order to become a qualified plumber.
Many plumbers and representatives of plumbing companies interviewed during this project complained that the current training system for plumbers is not effective and does not produce plumbers in adequate numbers.

\section{Insurance industry}

The insurance industry plays a large role in the plumbing industry. According to Clayton (2005) geyser failures cost the insurance industry up to R300 m. a year in claims. The number of geysers installed monthly is estimated at between 30000 and 40 000. Most of the failures are reported to occur due to incorrect installation rather than component failure. As a result, the insurance industry can play a significant role in ensuring compliance by requiring that only compliant components are installed in all buildings they insure, and ensuring that only compliant components are installed when honouring claims.

\section{Legal requirements for plumbing components}

The Water Services Act (RSA, 1997) allows the Minister of Water Affairs and Forestry to prescribe from time to time compulsory national standards relating to many aspects, including the requirement for persons who shall install and operate water services works and the construction and functioning of water services works and consumer installations. Such standards were published for the plumbing industry under Government Notice No R. 509 of 8 June 2001 entitled Regulations Relating to Compulsory National Standards and Measures to Conserve Water (DWAF, 2001). Article 14 of this document requires that: 'Every consumer installation must comply with SANS 10252: Water Supply and Drainage for Buildings and SANS 10254: The Installation of Fixed Electric Storage Water Heating Systems, or any similar substitution re-enactment or amendment thereof if the consumer installation is of a type regulated by either standard.'

The Water Services Act also gives the power and responsibility to WSAs to make and enforce water bylaws, and provides for the Minister of Water Affairs and Forestry to propose model bylaws as a guide for Water Services Authorities. The Model Water Services Bylaws was published by the Minister of Water Affairs and Forestry in August 2000 (DWAF, 2000).

The Model Water Services Bylaws recommend that each WSA should maintain a Schedule of Approved Pipes and Fittings. Only the pipes and components included in this Schedule are allowed to be used in the given WSA's areas of supply. Any other component not included in this Schedule requires written authorisation by the WSA or its authorised agent before it can be used. The WSA has the right to impose additional conditions on plumbing components included in the Schedule, but is bound by the Water Services Act, and thus may not include components that do not comply with SANS 10252 or 10254.

As part of this study, the water bylaws of 19 of the 169 WSAs were obtained and analysed. These were mainly the larger WSAs, and combined serve around $43 \%$ of the South African households. According to Still et al (2008), the smaller the WSA, the less likely it is to have updated its bylaws.

For almost all the bylaws analysed, a pipe or component is included in the Schedule of Approved Products if it bears the SABS mark or has an SABS Certificate of Compliance. Four of the bylaws studied (Cape Town, Richards Bay, Tshwane and Nelson Mandela Bay) accept the JASWIC list of approved products. The water bylaws of the Mbombela, Emfuleni and Makala Municipalities specify that a plumbing component should be included by the municipality in the Schedule if 'deemed acceptable by the Municipality', but does not list specific components, 
and thus leaves these bylaws open to abuse. Most bylaws specify that plumbing work shall be done only by a qualified plumber or a person working under the supervision of a qualified plumber. Two municipalities (eThekwini and Cape Town) go further by recommending the registration of plumbers. Most bylaws give an authorised agent of the municipality the right to enter any premises for inspection purposes.

According to an internal JASWIC document (JASWIC, 2008b) 'very few, if any' WSAs maintain their own schedules, and most rely on the JASWIC schedule. Some refer to it directly in their bylaws and others by means of council resolutions. This was borne out by the fact that we were unable to identify any WSA with its own lists of approved components in this project.

In this study, a plumbing component was taken to be compliant if it bore the SABS mark, or was included in the JASWIC list of approved products.

\section{Discussion}

The Water Services Act makes it illegal to install any plumbing component that does not comply with the relevant specifications listed in the latest versions of SANS 10252 and 10254 . However, compliance does not mean that the component has to bear the SABS mark. WSAs have the right to impose their own requirements through bylaws and maintain their own schedules of approved components, as long as these components can also be shown to comply with SANS 10252 and 10254. JASWIC ensures compliance of non-SABS mark holders by requiring suppliers of these components to enter into a standard contract with the SABS, ensuring that regular inspections and compliance tests are carried out.

An important point is that the law does not prohibit the import and sale of non-compliant components, but only the installation thereof. The responsibility for enforcing the law is thus placed solely on the shoulders of local authorities, who should ensure compliance through measures such as maintaining a schedule of approved components, site visits, building inspections and registration of plumbers. However, it became clear throughout this project that very few municipalities actually enforce the laws on plumbing components, and that many non-compliant plumbing components are being installed in buildings. Only one local authority, namely that of Cape Town, was found to have a system of water inspectors to specifically enforce compliance to their water bylaws.

One of the main reasons for the lack of enforcement is the severe shortage of technical staff at local government level. Lawless (2007) found that local governments in South Africa have on average 3 civil engineering professionals (engineers, technologists and technicians) per 100000 population, which compares very unfavourably with around 22 civil engineering professionals per 100000 population in developed countries. In addition, around $30 \%$ of municipalities in South Africa have no civil engineering professional employed.

The Institute of Plumbing South Africa has recently initiated a scheme whereby plumbers are registered and the quality of their work inspected to ensure compliance (IOPSA, 2008c). This type of self-regulation by the plumbing industry can assist in addressing the problems being experienced due to lack of capacity at local government level, especially if it is supported by institutions such as the insurance industry and Government.

\section{The level of compliance in South Africa}

A number of different methods were employed to estimate the level of compliance of plumbing components in South Africa:

- Information on plumbing components available on the market was gathered and analysed

- A questionnaire-based survey was conducted on plumbers

- Representatives of a number of local plumbing manufacturers were interviewed

- A limited investigation was done to approximate the availability and price of non-compliant plumbing components at different retailers

- A limited investigation was conducted to approximate the level of compliance in low-cost housing developments

- An analysis of the level of compliance was done for a rural water supply project in Venda

The above methods and their findings are discussed in this section.

\section{Investigation of plumbing components on the market in South Africa}

Manufacturers and distributors have to market their components in order to sell them. This provides an opportunity to collect information on plumbing components available on the local market. The search for plumbing components in this study consisted mainly of a web-based search, but also included the analyses of component catalogues and visits to plumbing suppliers. The list of components found was checked against the SABS and JASWIC schedules to determine whether they are compliant components, and whether their claims of compliance were accurate.

A total of 2626 plumbing components for sale on the market were identified and investigated. The results are summarised in Table 1. Valves showed the lowest level of compliance (17\%), while taps showed the highest (48\%). Overall, 1512 or 58\% of the components investigated were found to be non-compliant. In addition, 6 companies claimed to be SABS mark holders while they were not included in the SABS list of mark holders. These companies supplied 269 (10\%) of the components found.

\begin{tabular}{|c|c|c|}
\hline \multicolumn{3}{|c|}{$\begin{array}{c}\text { TABLE } 1 \\
\text { Compliance of plumbing components available on } \\
\text { the market in South Africa }\end{array}$} \\
\hline Component & $\begin{array}{c}\text { No of components } \\
\text { found }\end{array}$ & $\begin{array}{c}\text { Level of } \\
\text { compliance }\end{array}$ \\
\hline Taps & 1370 & $48 \%$ \\
\hline Bidets & 272 & $29 \%$ \\
\hline Cisterns & 63 & $37 \%$ \\
\hline Pipes & 497 & $43 \%$ \\
\hline Showers & 383 & $36 \%$ \\
\hline Geysers & 35 & $37 \%$ \\
\hline Valves & 36 & $17 \%$ \\
\hline Total / Average & 2656 & $42 \%$ \\
\hline
\end{tabular}

\section{Survey of plumbers}

Plumbers are knowledgeable on both the legal requirements for plumbing components and the compliance of specific plumbing components, and were thus considered a good source of information on the state of the plumbing industry. A questionnairebased plumbers' survey was conducted to gain insight into practices in the industry.

A number of strategies were followed to get the questionnaires completed: plumbers were contacted by phone and the questionnaire faxed to them. This approach resulted in few 
replies and was abandoned. Plumbers were also approached at IOPSA regional meetings, with the research team working via the IOPSA regional chairs to attend meetings where possible. The response at IOPSA meetings was generally good and the bulk of completed questionnaires were collected in this way. A special effort was made to obtain responses from informal plumbers that were not part of the mainstream plumbing industry. Visits were made to stores selling plumbing components and informal plumbers were approached when they visited the stores. Generally the merchants were not supportive and did not allow such interviews to be conducted outside their stores. Visits were then made to known areas where informal plumbers would wait to be picked up for employment. Approximately 10 survey forms were completed by informal plumbers. However, the informal plumbers were visibly uncomfortable with the questioning and it is likely that some of their answers reflected what they thought the answer should be, rather than their actual practices.

In total, 100 completed survey forms were obtained and analysed. The minimum number of data points required to take a result as a reflection of practices in the industry was taken as 20 . Since most of the forms were completed by plumbers active in IOPSA (68\% of the respondents were IOPSA members, and are thus obliged to only use compliant plumbing components), the results may be biased towards more responsible plumbers, and will thus be conservative.

Most (75\%) of the respondents were qualified plumbers, i.e. they either had a Plumbing Trade Certificate ( $61 \%$ of respondents), or a National Certificate in Construction at NQF level 3 (14\% of respondents). Eleven per cent of the respondents were plumbers-in-training, and the remaining $14 \%$ did not have any formal training.

Figure 1 shows the type of areas in which the respondents did their plumbing work. The respondents did most (33\%) of their plumbing work in suburbs, followed by commercial (19\%) and industrial areas (16\%). Townships and informal settlements were responsible for 13 and $8 \%$ of plumbing work respectively. The low fraction for townships is probably a result of fewer plumbers from these areas attending IOPSA meetings, which were mainly held in suburban areas.

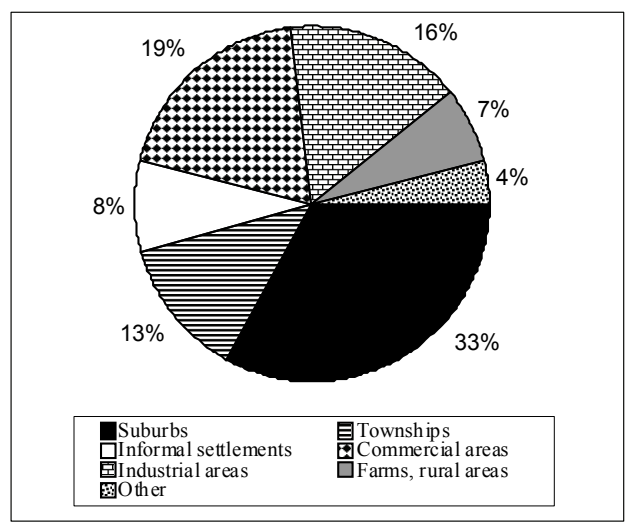

Figure 1

Distribution of plumbing work by area type

Figure 2 shows the type of buildings in which the respondents did their plumbing work. Most (29\%) of the work was done in private households, followed by commercial buildings (21\%). The remaining $50 \%$ is roughly equally divided between public, industrial and tourism industry buildings.

Figure 3 shows the type of plumbing work performed by the respondents. It shows that while the type of work is roughly

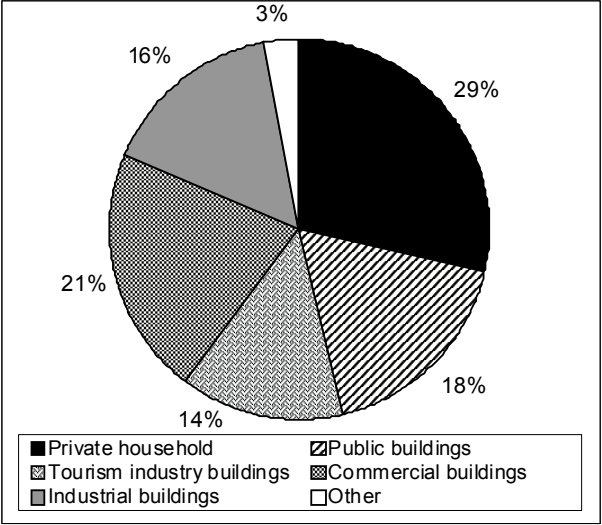

Figure 2

Distribution of plumbing work by building type

equally distributed, most (39\%) plumbing work is done in maintenance, followed by new installations (35\%) and then renovations (26\%).

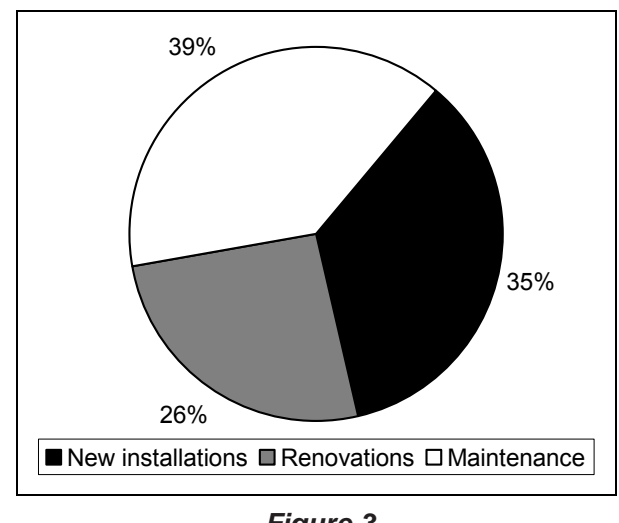

Distribution of plumbing work by type of work

The extent of non-compliant components installed in South Africa was judged by asking the respondents the question: 'Considering all plumbing components installed in South Africa, what fraction do you believe to be approved by SABS, JASWIC or a local authority?' The result of this question is shown in Fig. 4: $37 \%$ of plumbers believe that all or most plumbing components are compliant. The remaining $63 \%$ of plumbers believe that an average (defined as between 34 and 67\%) or fewer components installed in South Africa are compliant. A weighted average of

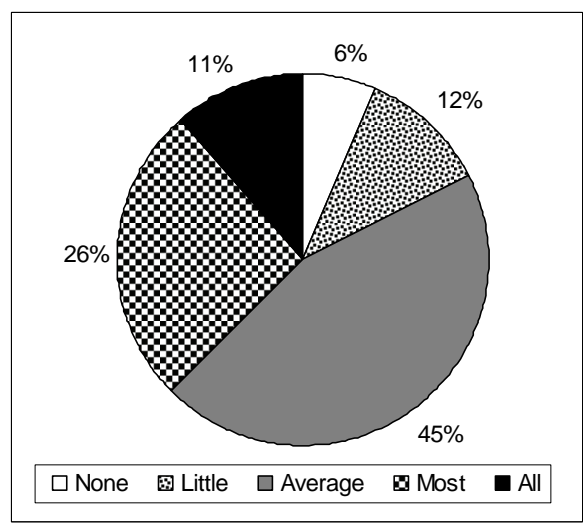

Figure 4

Extent of compliant plumbing components installed in South Africa 


\begin{tabular}{|l|c|c|c|}
\hline \multicolumn{4}{|c|}{ TABLE 2 } \\
Compliance of plumbing components by type of plumbing work \\
\hline \multirow{2}{*}{ Type of plumbing work } & \multicolumn{2}{|c|}{ Fraction of compliant components installed } \\
\cline { 2 - 4 } & Little or None & Average & Most or all \\
\hline New installations & $49 \%$ & $30 \%$ & $21 \%$ \\
\hline Renovations & $19 \%$ & $43 \%$ & $38 \%$ \\
\hline Maintenance & $18 \%$ & $43 \%$ & $39 \%$ \\
\hline
\end{tabular}

\begin{tabular}{|l|c|}
\hline \multicolumn{2}{|c|}{ TABLE 3 } \\
\hline Comment & No of respondents \\
\hline Better training and more qualified plumbers required & 22 \\
\hline Only qualified plumbers should be allowed to do plumbing work & 11 \\
\hline Better or more inspection by local authorities (e.g. water inspectors) & 9 \\
\hline One central body should exist and have the power to control plumbers & 7 \\
\hline Better policing and regulation of the industry & 7 \\
\hline A plumber registration or licensing system & 6 \\
\hline Only SABS approved components should be sold & 4 \\
\hline
\end{tabular}

the responses provides an estimate of $43 \%$ non-compliant components being installed in South Africa.

A similar question was asked aimed at plumbers rather than plumbing components: the weighted average of the responses provides an estimate that $52 \%$ of plumbers install non-compliant components.

An interesting correlation was found between the type of plumbing work and the fraction of compliant components installed. A cross-tabulation between the results of these two questions is shown in Table 2. This table indicates new installations to be the biggest problem, with $79 \%$ of the respondents indicating that average or fewer plumbing components are compliant.

The survey form ended with an open request for suggestions on how the plumbing industry in South Africa can be improved or better regulated. Table 3 shows the comments most frequently made. It is clear that plumbers would like to see better regulation and policing of plumbers and plumbing work. This can be understood if it is recognised that a plumber that installs cheaper noncompliant components will be able to undercut ethical plumbers, and thus take work away from them. The ethical plumber is then left with a choice between being ethical and getting work, which inevitably leads to more non-compliant components being installed. The only way to stop this downward spiral is for Government (national, provincial and local) to ensure that the relevant laws are enforced rigorously.

\section{Interviews with local manufacturers and importers}

Interviews were conducted with representatives of four local manufacturers and one importer of plumbing components with the aim of getting their views on the effects of non-compliant imported plumbing components on the local market. The findings are summarised below:

- The import of sub-standard and non-compliant components negatively affects local manufacturers, whose components cost more because of the need to comply with SABS standards. They are obliged to lower the profit margins in order to keep the market share, and South African job losses occur in the sector as a result.

- Local manufacturers agree with the notion that roughly $50 \%$ of components installed in South Africa are non-compliant
- The biggest problem in the plumbing industry is insufficient enforcement of existing legislation

- Changes that they would like to see include better enforcement of legislation, improved control of imports, improved plumber training and better control of plumbers through a registration system.

\section{Price comparison}

Price is a main driver of purchases in the free market and provides a strong incentive for consumers to purchase cheaper non-compliant components. To approximate the availability and price of non-compliant components at retailers, ten retailers selling plumbing components in the Johannesburg and Soweto areas were investigated. Three of the retailers were large building suppliers, five hardware stores, and two specialist plumbing suppliers. The following components were included in the study: angle valve, standard $20 \mathrm{~mm}$ garden tap, single $15 \mathrm{~mm}$ kitchen tap, kitchen sink mixer tap and toilet cistern components. Only SABS compliance was investigated.

It was found that hardware stores had the most non-compliant components, followed by building suppliers. The specialist plumbing suppliers visited did not sell any non-compliant components.

It was found that all SABS compliant components are equal in price or (up to 135\%) more expensive than non-compliant components. On average, SABS compliant components were approximately 50\% more expensive than non-SABS compliant components. A clear price incentive exists from the viewpoint of the consumer, who might well be unaware of the legal requirements to purchase and install non-compliant components.

\section{Low-cost housing developments}

Visits were made to one house in each of 10 different low-cost housing developments in the Tshwane and Johannesburg areas to approximate the level of compliance of plumbing components installed in these types of developments. Permission was asked of the house tenant to inspect the plumbing components, after which the outside taps, inside taps and toilet flushing mechanisms (as applicable) were inspected. The average age of the houses inspected was 1.5 years, and a total of 26 plumbing 
components were inspected. The following findings were made:

- $80 \%$ of the houses did not have an angle or shut-off valve installed for the toilet

- $40 \%$ of the houses had no tap inside the house

- $92 \%$ of the components inspected were non-compliant

- $61 \%$ of the non-compliant components were broken or leaking

- $50 \%$ of the toilets were leaking.

The data from this limited scope study indicate that the plumbing components installed in low-cost housing are notably inferior. The lack of quality is clearly reflected in the fact that more than $50 \%$ of the components were broken or leaking, and that $50 \%$ of the toilets were leaking. The severity of the problem is highlighted by the fact that the average house age at the time of inspection was only 1.5 years.

Low-cost housing is supplied to poor and vulnerable people, who can often not afford to replace faulty plumbing components and pay large water accounts due to leakage. It is thus of the greatest importance that low-cost houses are fitted with highquality plumbing components that will operate with minimum maintenance for many (say in excess of 20) years. The investigation of low-cost units showed that this requirement is not being met in the least. In addition, the legal requirements for plumbing components are largely being ignored, resulting in components failing after short periods of time and a very negative outlook for leakage in low-cost developments. Further work is required to determine the extent of the problem in low-cost houses around the country, but at the same time, urgent action is required to improve the situation.

\section{Rural water supply system}

A study on rural water supply was done by Haarhoff and Rietveld (2008) in 21 villages with 9000 inhabitants in the Upper Nwanedi Basin in Venda during October 2007. The area is served by 108 public standpipes (with one or two taps) serving between 4 and 30 households each. The area has a dedicated maintenance officer responsible for repairing or replacing broken taps, even though it was found that he lacked some basic tools to perform his work.

Various problems with taps were observed, including broken handles, stripped threads on valve spindles, leaking gland seals and worn washers. The first two problems render a standpipe unusable, while the latter two cause intermittent or continuous leakage from the tap.

Of the 108 standpipes supplying the area, $45 \%$ had compliant taps, $41 \%$ non-compliant taps and $13 \%$ no taps at all. Only $4 \%$ and $9 \%$ of the standpipes with taps were found to be leaking and broken respectively. This relatively low fraction is probably due to a dedicated maintenance officer looking after the taps in the area. However, this officer does not purchase taps or tap components himself, and thus the local water supply authority is directly responsible for supplying the large fraction of noncompliant components. Thus, in this case the very authority that is tasked with enforcing legislation on plumbing components is responsible for supplying the non-compliant components.

Haarhoff and Rietveld (2008) concluded that the tap is the most important component of a standpipe installation and has to be exceptionally robust to withstand the high wear and tear due to frequent use, occasional abuse and some vandalism. They recommended that special specifications and maintenance requirements are developed and enforced for standpipes to ensure that poor rural communities are provided with an adequate water supply and that water leakage is minimised. Even if this means a substantial increase in the cost of the taps, the additional cost is likely to be negligible compared to the cost of the whole supply system and the consequences of not supplying rural people with a sustained and adequate level of service.

\section{Discussion and conclusions}

High-quality plumbing systems are essential to ensure that water supplied to homes is used effectively, and leakage is minimised. South African law is clear that only plumbing components that comply with certain standards (SANS 10252 and SANS 10254) are allowed to be installed in South Africa. However, a number of worrying trends were found in this study that do not support the provision of high-quality plumbing systems and may have severe implications for future water demand and leakage in South Africa.

The main aim of this study was to quantify the extent of non-compliant plumbing components installed in South Africa. It was found that a substantial fraction, approximately $50 \%$, of plumbing components installed do not comply with the legal requirements. This is evident from the following findings:

- $58 \%$ of the plumbing components available on the market were found to be non-compliant

- According to a survey of plumbers, $43 \%$ of components installed are non-compliant and 52\% of plumbers install non-compliant components

- In interviews with representatives of local manufacturers, the representatives agreed that around $50 \%$ of components installed are non-compliant

- A preliminary investigation into plumbing components installed in RDP houses indicated that more than $90 \%$ of components are non-compliant.

The main reasons for the high level of non-compliance are considered to be the lack of enforcement of the legislation at local government level and the fact that there is no prohibition on the import and sale of non-compliant components. In some instances where national and local government play leading roles in service provision to the poor (in particular low-cost housing and rural water supply), the problem of non-compliance was found to be particularly bad and even government institutions purchases non-compliant components.

The consequences of such a high fraction of non-compliant plumbing components are dire and include:

- Undermining authority of government and the law if government does not comply with its own rules

- Potential negative health impacts by contamination of the drinking water through failed components or leaching of chemicals such as lead, iron, arsenic, copper from plumbing components made from sub-standard materials

- Higher fail frequencies and shorter life-spans of plumbing components, resulting in greater future damage to property and higher water losses. This was evident in the investigation of RDP houses, where the majority of non-compliant components failed in a very short period of time (less than 1.5 years) and $50 \%$ toilets were found to be leaking already.

- Undermining of the local plumbing manufacturing industry, resulting in closure of manufacturing facilities and job losses, since they are not able to compete in a fair manner with imported poor- quality and non-compliant components.

The following recommendations are made to improve the situation: 
- The import and sale of non-compliant components should be restricted

- Plumbing legislation should be enforced at local government level through a system of trained water inspectors

- National, Provincial and Local Government structures should lead by example through complying with legislation regarding plumbing components

- A national workshop involving Government at all levels, the plumbing industry and related organisations to discuss the way forward to manage this problem

- A plumbing compliance certificate should be required when transfer of ownership of properties occur

- Better control of plumbers, such as a national register of qualified plumbers, should be enforced

- Better training of plumbers should be implemented, and the training process should be streamlined to increase the numbers and quality of new plumbers entering the trade

- The plumber registration scheme instituted by the Institute of Plumbing South Africa should be supported by the Insurance Industry and Government

- A media campaign should be launched to inform people of the importance and requirements of plumbing components

- The SABS should make information on compliance of specific plumbing components available to the public and enforce the proper use of their mark

- Insurance companies have to require compliance when insuring properties, and ensure compliance when honouring claims.

\section{Acknowledgements}

The authors would like to thank the South African Water Research Commission for financially supporting the research under the project K5/1702, as well as Mr. Gugu Sidinile who assisted with some field investigations.

\section{References}

BBC News (2008) Focus on Baby Death Safety Checks. Available from http://news.bbc.co.uk/1/hi/england/somerset/7179092.stm (Accessed 02 July 2008)

CLAYTON C (2005) Approved Security Products Lower Your Premiums. Available from http://http.persfin.co.za/index.php?fSectionId= 594\&fArticleId=2373749 (Accessed 08 January 2008).

DPW (Department of Public Works) (2007) Skills for infrastructure delivery in South Africa: the challenge of restoring the skills pipeline. Available from http://www.publicworks.gov.za/attachments/ skills for infrastructure delivery.pdf (Accessed 21 February 2008).

DWAF (Department of Water affairs and Forestry) (2000) Model Water Services Bylaws. DWAF, Pretoria, South Africa.

DWAF (2001) Regulations relating to compulsory national standards and measures to conserve water. Government Notice. (No R 509). DWAF, Pretoria, South Africa.
DWAF (2007) Available from http://www.dwaf.gov.za/ (Accessed 27 March 2007). DWAF, Pretoria, South Africa.

DWAF (2008) Free Basic Water. Available from http://www.dwaf.gov. za/FreeBasicWater/ (Accessed 01 April 2008). DWAF, Pretoria, South Africa.

DWAF and SALGA (Department of Water affairs and Forestry and South African Local Government Association) (2007) Water Services Authority Legislative Handbook. South Africa.

EPA (United States - Environmental Protection Agency) (2007) Lead and Copper Rule. Available from http://www.epa.gov/safewater/ lcrmr/index.html (Accessed 26 March 2008).

FRANKEL M (2004) Facility Piping Systems Handbook (2 ${ }^{\text {nd }}$ edn.) Downloaded from Digital Engineering Library @ McGraw-Hill.

HAARHOFF J and RIETVELD L (2008) Standpipe design for rural South Africa. Manuscript submitted for publication. J. SA Inst. of Civil Eng. 51 (1).

IOPSA (Institute of Plumbing South Africa) (2008a) About the Institute of Plumbing. Available from http://www.iopsa.org.za/iopsa_about_ us.htm (Accessed 14 January 2008).

IOPSA (2008b) Members Code of Conduct Agreement. Available from http://www.iopsa.org.za/Documents/code of conduct.pdf (Accessed 16 April 2008).

IOPSA (2008c) Plumber registration. Plumbing Africa Vol.14 (6) August 2008.

JASWIC (1999) General Policy. Available from http://www.wrc.org.za/ downloads/jaswic/policy.htm (Accessed 21 January 2008)

JASWIC (2008a) JASWIC Constitution. Available from http://www.jaswic.co.za/constitution.pdf (Accessed 14 January 2008).

JASWIC (2008b) The Joint Acceptance Scheme For Water Services Installation Components (unpublished).

JORDAN M (2004) SA Plumbers' Handbook. South Africa: Pipe Trades Media Group, Edenvale, South Africa.

LAWLESS A (2007) Numbers \& Needs in Local Government,. SAICE, Midrand, South Africa.

STILL D, ERSKINE S, WALKER N and HAZELTON D (2008) The Status and Use of Drinking Water Conservation and Savings Devices in the Domestic and Commercial Environments in South Africa. WRC Report No TT 358/08.Water Research Commission Pretoria, South Africa.

RSA (1997) The Water Services Act No 108 of 1997. Government of South Africa.

THOMPSON T, FAWELL J, KUNIKANE S, JACKSON D, APPLEYARD S, CALLAN P, BARTRAM J and KINGSTON P (2007) Chemical Safety of Drinking Water: Assessing Priorities for Risk Management. WHO Press, Geneva, Switzerland.

UNEP (United Nations Environment Programme) (1999) Global Environment Outlook 2000. Available from http://www.unep.org/ Geo2000/english/i42a.htm (Accessed 05 September 2008).

WHO (World Health Organization) (2006) Health Aspects of Plumbing. WHO Press, Geneva, Switzerland.

WRC (Water Research Commission) (2008) Water in South Africa. Available from http://www.wrc.org.za/downloads/education/ Water\%20in\%20SA.pdf (Accessed 30 July 2008). Water Research Commission, Pretoria, South Africa. 